\title{
Test Plan for Solvent Extraction Data Acquisition to Support Modeling Efforts
}

Veronica Rutledge Kristi Christensen

Troy Garn

Jack Law

December 2010

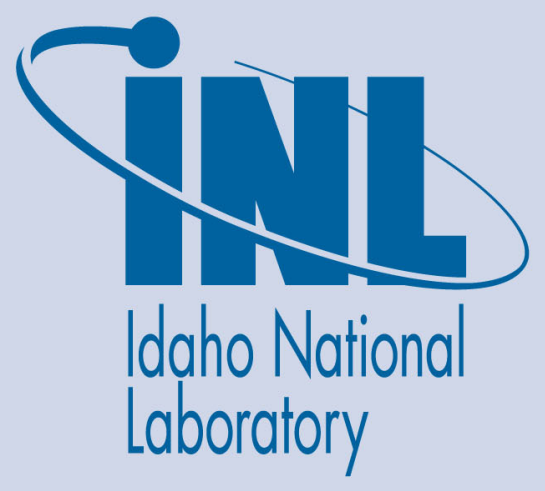

The INL is a U.S. Department of Energy National Laboratory operated by Battelle Energy Alliance 
INL/EXT-10-20687

FCR\&D-SEPA-2011-000021

\title{
Test Plan for Solvent Extraction Data Acquisition to Support Modeling Efforts
}

\author{
Veronica Rutledge \\ Kristi Christensen \\ Troy Garn \\ Jack Law
}

December 2010

\author{
Idaho National Laboratory \\ Fuel Cycle Research \& Development \\ Separations and Waste Forms \\ Idaho Falls, Idaho 83415 \\ http://www.inl.qov
}

Prepared for the

U.S. Department of Energy

Office of Nuclear Energy

Under DOE Idaho Operations Office

Contract DE-AC07-05ID14517 


\section{DISCLAIMER}

This information was prepared as an account of work sponsored by an agency of the U.S. Government. Neither the U.S. Government nor any agency thereof, nor any of their employees, makes any warranty,

expressed or implied, or assumes any legal liability or responsibility for the accuracy, completeness, or usefulness, of any information, apparatus, product, or process disclosed, or represents that its use would not infringe privately owned rights. References herein to any specific commercial product, process, or service by trade name, trade mark, manufacturer, or otherwise, does not necessarily constitute or imply its endorsement, recommendation, or favoring by the U.S. Government or any agency thereof. The views and opinions of authors expressed herein do not necessarily state or reflect those of the U.S. Government or any agency thereof. 


\section{Table of Contents}

List of Acronyms nan.

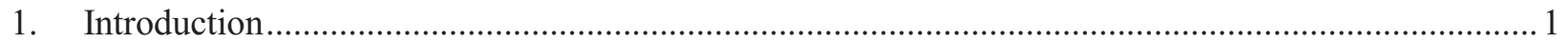

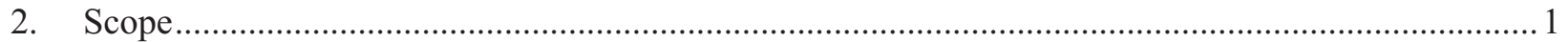

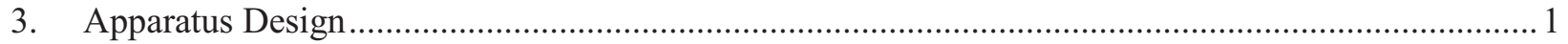

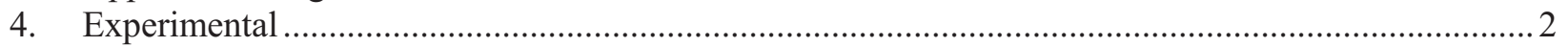

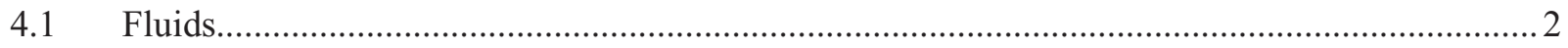

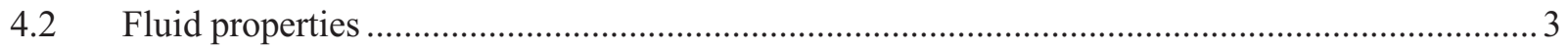

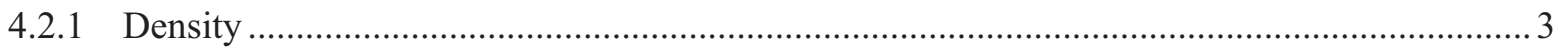

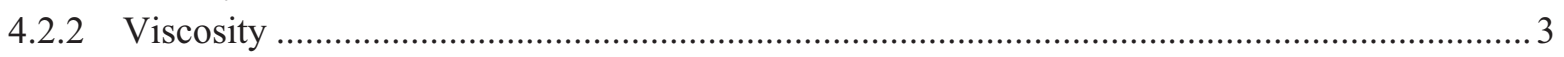

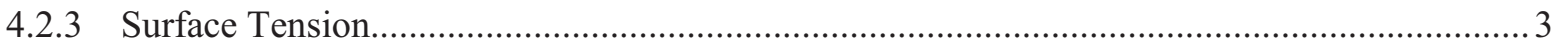

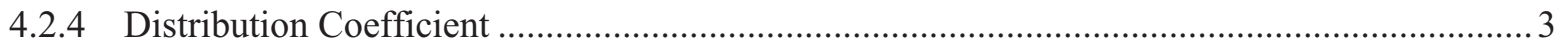

4.2.5 Diffusion Coefficient ...................................................................................................... 3

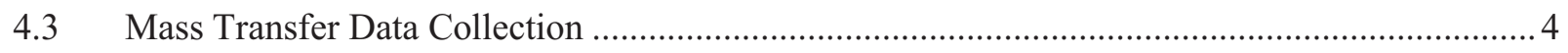

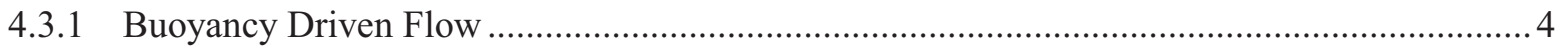

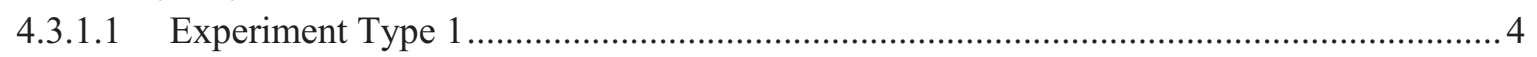

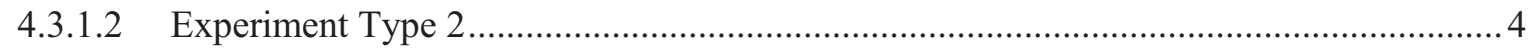

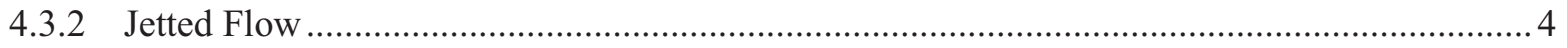

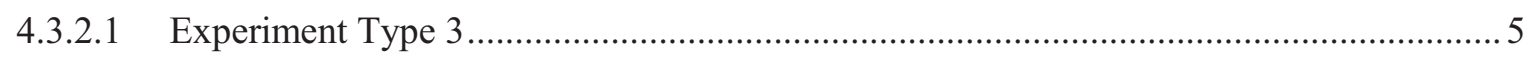

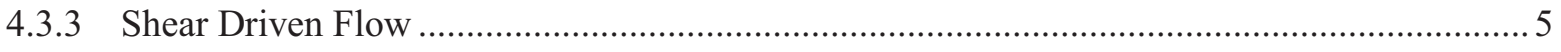

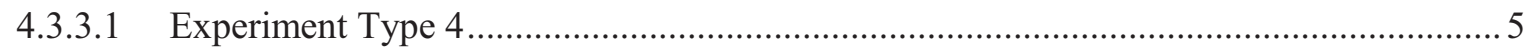

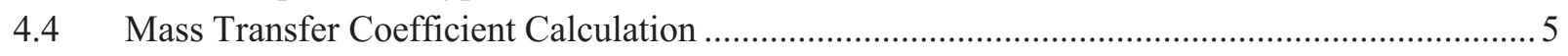

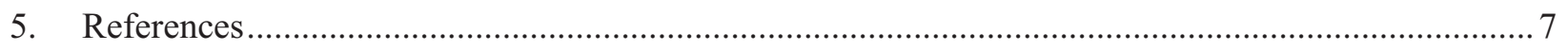

\section{Figures}

Figure 1. Schematic of the Experimental Apparatus .............................................................................

\section{Tables}

Table 1. Experimental Test Design................................................................................................... 


\section{List of Acronyms}

CMPO Octyl(phenyl)-N,N-diisobutylcarbamoylmethyl-phosphine Oxide

$\mathrm{HNO}_{3} \quad$ Nitric Acid

ICP-MS Inductively Coupled Plasma - Mass Spectroscopy

INL Idaho National Laboratory

LANL Los Alamos National Laboratory

LLE Liquid-Liquid Extraction

NEAMS Nuclear Energy Advanced Modeling and Simulation

SafeSep Safeguards and Separations

SX Solvent Extraction

TBP Tri-n-Butylphosphate

TRUEX TRansUranic Extraction 


\section{Proposed Test Plan for SX Data Acquisition FY-11}

\section{Introduction}

In support of the NEAMS SafeSep modeling effort, the Idaho National Laboratory (INL) is working in collaboration with Los Alamos National Laboratory (LANL) to further develop accurate simulations of droplet dynamics in association with mass transfer in a two phase liquid-liquid extraction (LLE) system. Research performed at the INL will provide requested data needed to support the model being developed at LANL. Understanding the association of droplet dynamics to mass transfer is of great importance in liquid-liquid extraction processes. These small scale phenomena can significantly affect interfacial surface area and, therefore, extraction efficiency. Droplet scale experiments and simulations will improve understanding of mass transfer at the droplet interface and will support modeling of LLE processes.

Droplet dynamics with mass transfer under buoyancy and shear driven flow are of initial interest. Buoyancy driven flow is relevant to the mechanism seen in pulse columns, and shear driven flow is relevant to that seen in centrifugal contactors and mixer-settlers.

\section{Scope}

This testing will support NEAMS SafeSep Modeling efforts related to droplet simulation in liquid-liquid extraction equipment. Physical characteristic determinations will be completed for the fluids being used in the experiment including viscosity, density, surface tension, distribution coefficients, and diffusion coefficients. Then, experiments will be carried out to provide data for comparison to the simulation's calculation of mass transfer coefficients.

Experiments will be conducted with solutions used in the TRansUranic EXtraction (TRUEX) process extraction section. The TRUEX process was chosen since it is one solvent extraction system currently proposed for the separation of actinides and lanthanides from used nuclear fuel, it is diffusion limited, and testing can be performed using non radioactive lanthanides to evaluate mass transfer. The extraction section involves transfer of one or more lanthanide species from an aqueous solution to an organic solvent.

Single droplets rising by buoyancy will be studied first. Droplet size and number of species transferred will be varied independently to provide mass transfer coefficients as a function of each variable. An apparatus has been designed specifically for these experiments. In order to get more accurate measurements of droplet size, contact time, time of droplet formation, and possibly droplet breakup and coalescence, a high speed camera will be utilized for these experiments. Other potential experiments include examining the effects of jetted droplets and shear flow on the mass transfer coefficients. These experiments may be included as time and funding allow.

\section{Apparatus Design}

The apparatus for performing the mass transfer experiments is show in Figure 1. The body is made of square glass tubing to eliminate distortions while imaging the rising droplets with the high speed camera. The needles are interchangeable allowing multiple needle diameters for controlling droplet size and 
variation of the needle height to adjust droplet rise time. The tapered organic collection chamber is designed to minimize droplet contact time with the aqueous phase, minimizing additional mass transfer after the rise time. A pump is attached to the organic inlet to control droplet formation rate and to provide for consistency in droplet size.

The apparatus is designed with an aqueous inlet and outlet for use in experiments with countercurrent aqueous flow. Additionally, the apparatus will be modified to include a baffle for these experiments. The baffle will distribute the aqueous flow to eliminate undesired crosscurrent flow. A recirculation pump will be used to control the aqueous flow rate.

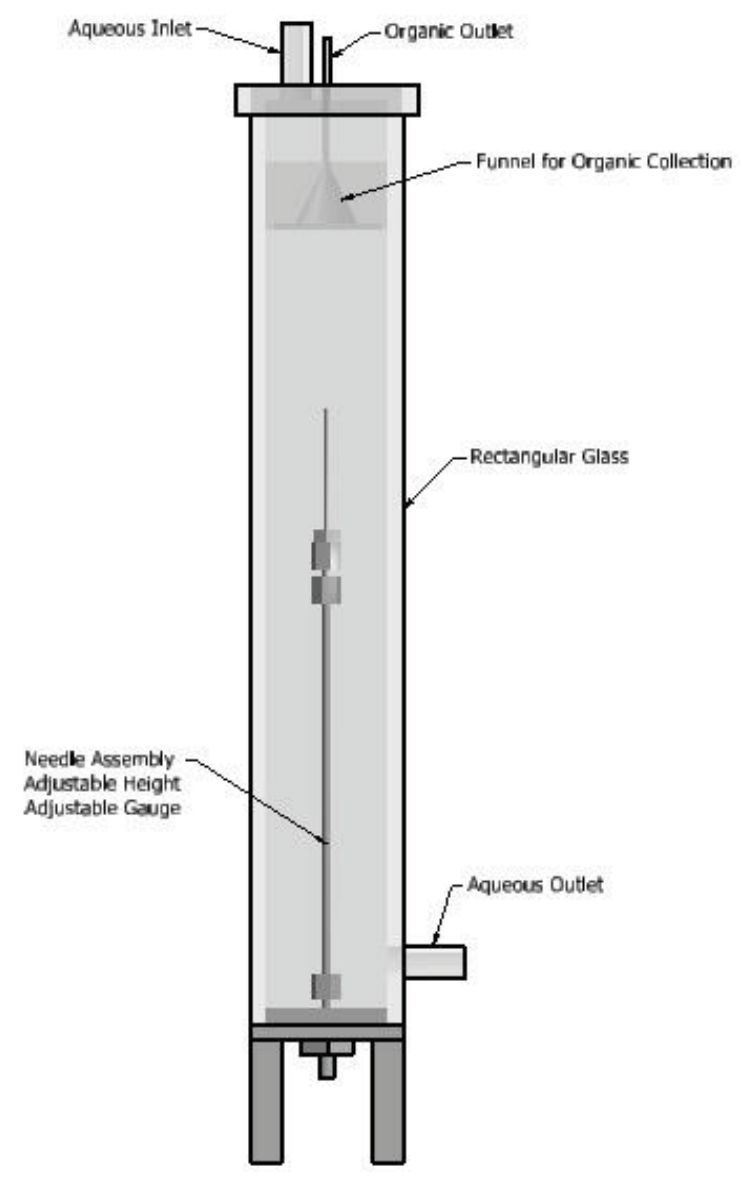

Figure 1. Schematic of the Experimental Apparatus

\section{Experimental}

\subsection{Fluids}

The fluids used for obtaining the data needed will be those used in the TRUEX process. The TRUEX solvent is the organic solution prepared as $0.2 \mathrm{M}$ octyl(phenyl)-N,N-diisobutylcarbamoylmethylphosphine oxide (CMPO) and $1.4 M$ tri-n-butylphosphate (TBP) in n-dodecane. Prior to performing tests, the organic solution will be pre-equilibrated with $3 \mathrm{M}$ nitric acid $\left(\mathrm{HNO}_{3}\right)$. Pre-equilibration will ensure the acid concentration in the solvent is at equilibrium mitigating the extraction of acid during mass transfer testing. The aqueous solution typically will be $3 \mathrm{MHNO}_{3}$ with cerium. Cerium will be used in 
the single species experiments in a 1 gram per liter concentration. In experiments with two mass transport species, 0.5 grams per liter cerium and 0.5 grams per liter lanthanum concentrations will be utilized.

\subsection{Fluid properties}

Prior to collection of mass transfer data, preliminary tests and calculations will be performed to ascertain fluid properties needed as input for the simulation. All fluid property measurements will be performed in triplicate in order to obtain accurate measurements. The organic phase fluid properties will be determined both before and after pre-equilibration with $3 \mathrm{MHNO}_{3}$.

\subsubsection{Density}

The densities of both fluids will be ascertained by weighing a known volume of the fluid.

\subsubsection{Viscosity}

The viscosity will be determined using a viscometer.

\subsubsection{Surface Tension}

Surface tension will be determined using any of the following techniques: contact angle measurements, the Whilhelmy plate method with an electrobalance, bubble tensiometer measurements, or sessile drop analysis.

\subsubsection{Distribution Coefficient}

The distribution coefficient will be determined by varying the species concentrations in a series of aqueous samples. The aqueous samples will be contacted with a known volume of organic solution. The mixture will be stirred to ensure equilibrium has been reached. An aliquot of each phase will then be analyzed by inductively coupled plasma - mass spectroscopy (ICP - MS) and distribution coefficients calculated. This parameter will be determined for cerium only and cerium and lanthanum together.

\subsubsection{Diffusion Coefficient}

Diffusion coefficients for the organic phase into the aqueous and cerium or lanthanum into either phase will be calculated using the Wilke - Cheng Equation:

$$
D_{A B}=7.4 \times 10^{-8} \frac{\left(\varphi M_{\left.w_{i} B\right)^{1 / 2} T}\right.}{\mu_{B} V_{A}^{0.6}} \mathrm{~cm}^{2} / \mathrm{s}
$$

Equation $1^{1}$

Where $\mathrm{D}_{\mathrm{AB}}$ is the diffusion of solute $\mathrm{A}$ into solvent $\mathrm{B}, \mathrm{M}_{\mathrm{w}, \mathrm{B}}$ and $\mu_{\mathrm{B}}$ are the molecular weight and viscosity of the solvent, respectively, $\varphi$ is a dimensionless solvent association factor, $\mathrm{V}_{\mathrm{A}}$ is the molal volume of the solute at its normal boiling point, and $\mathrm{T}$ is temperature. The solvent association factor of water is 2.6 and of non-hydrogen-bonded solvents such as organic liquids is $1^{1}$.

The Wilke-Cheng Equation is only valid for dilute amounts of solute. The diffusion of the aqueous phase into the organic phase is better estimated using the Stokes - Einstein Equation:

$$
D_{A B}=\frac{k_{B} T}{6 \pi \mu_{B} r_{d}}
$$

Equation $2^{1}$

Where $r_{d}$ is the radius of the diffusion molecule and $k_{B}$ is Boltzmann's constant. 


\subsection{Mass Transfer Data Collection}

Mass transfer data collection will begin with buoyancy driven flow, followed by jetted flow and shear flow as time and funding allow. Within each type of flow, there will be multiple variables that may be adjusted depending on the results of the previous experiments and whether it is deemed necessary by the researchers.

Multiple organic droplets will be needed to collect a large enough sample for analysis by ICP-MS. When performing the single droplet experiments, each droplet will be introduced into the aqueous phase allowing sufficient distance between droplets to avoid interaction and act as single droplets. Drops will coalesce in the organic collection chamber to provide sufficient volume for analysis.

Six different rise times will be used for each experiment in order to more accurately determine mass transfer coefficients as a function of rise time. The shortest rise time will be used as a reference point for calculation of the mass transfer coefficient, therefore, eliminating mass transfer during droplet formation.

A high speed camera will be used to obtain more accurate data. This will allow for more exact droplet size and rise time measurements and may also provide droplet deformation information. It is presumed that the droplet rise time will be a fraction of a second, and therefore, immeasurable using a stopwatch, making a high speed camera necessary for testing.

An experimental test design was completed to guide selection of testing conditions and is included below (Table 1). This test design is not all inclusive and may be modified as results deem necessary.

\subsubsection{Buoyancy Driven Flow}

Buoyancy driven flow will be the first type of flow used for mass transfer data collection. This type of flow is relevant to pulse column LLE. There will be two experiments performed using this flow type.

\subsubsection{Experiment Type 1}

The first type of experiment with buoyancy driven flow will be single organic droplet experiments with no countercurrent aqueous flow. Droplet size and number of species will be the changing variables. There will be three droplet sizes used, and there will be either one or two species being transferred between phases. The data provided by experiment type 1 are mass transfer coefficients as a function of rise time, concentration as a function of time, and the effect of droplet size and the number of species on mass transfer coefficient and concentration.

\subsubsection{Experiment Type 2}

The second experiment with buoyancy driven flow will be single droplet experiments with countercurrent aqueous flow. The aqueous flow rate will be varied to determine the effect of countercurrent flow on the mass transfer coefficient, concentration, and droplet rise time. Droplet size and number of species may also be varied within this experiment type.

\subsubsection{Jetted Flow}

The second type of flow will be jetted flow, which is also relevant to pulse column LLE. There will be an added velocity to the droplets when they are introduced into the continuous phase. 


\subsubsection{Experiment Type 3}

The experiment type performed with a jetted flow will initially have no countercurrent flow. The velocity at which the droplet is jetted into the aqueous phase will be varied, resulting in determining mass transfer coefficients as a function of velocity. The droplet size, number of droplets, and number of species may also be adjusted.

\subsubsection{Shear Driven Flow}

The third and final type of flow to be tested will be shear driven flow which is relevant to contactor LLE. This type of experiment will include the introduction of a shear created by a moving plate within the apparatus. Experiments with shear flow will require a modified or new apparatus that contains a moveable plate and will be performed based on available time and funding.

\subsubsection{Experiment Type 4}

This final experiment type will begin with a single droplet and no countercurrent aqueous flow. It will then progress depending on initial results, available time, and funding. The variables that may be varied will be plate velocity, the direction of plate movement, droplet size, number of droplets, number of species, and whether or not there is a countercurrent flow. The use of the high speed camera will allow for the imaging of the breakup and coalescence of the droplets due to the shear. The data obtained from this experiment type are mass transfer coefficients of species being transferred into organic droplets under shear and droplet deformation. While buoyancy driven and jetted flow data collection is being performed, development of shear experiments will be ongoing.

Table 1. Experimental test design for solvent extraction mass transfer data. Each experiment listed will be performed at 6 rise distances. Shear experiments have been excluded from this test design. *To be determined and, therefore, represented by the numbers $1-3$.

\begin{tabular}{|c|c|c|c|c|c|}
\hline Experiment & $\begin{array}{c}\text { Number } \\
\text { of Species }\end{array}$ & Flow Type & $\begin{array}{c}\text { Droplet } \\
\text { Size* }^{*}\end{array}$ & $\begin{array}{c}\text { Droplet } \\
\text { Velocity* }\end{array}$ & $\begin{array}{c}\text { Aqueous } \\
\text { Flow rate* }^{*}\end{array}$ \\
\hline 1 & 1 & Buoyancy & 1 & N/A & None \\
\hline 2 & 1 & Buoyancy & 2 & N/A & None \\
\hline 3 & 1 & Buoyancy & 3 & N/A & None \\
\hline 4 & 2 & Buoyancy & 1 & N/A & None \\
\hline 5 & 2 & Buoyancy & 2 & N/A & None \\
\hline 6 & 2 & Buoyancy & 3 & N/A & None \\
\hline 7 & 1 & Buoyancy & 1 & N/A & 1 \\
\hline 8 & 1 & Buoyancy & 1 & N/A & 2 \\
\hline 9 & 1 & Buoyancy & 1 & N/A & 3 \\
\hline 10 & 1 & Jetted & 1 & 1 & None \\
\hline 11 & 1 & Jetted & 1 & 2 & None \\
\hline 12 & 1 & Jetted & 1 & 3 & None \\
\hline
\end{tabular}

\subsection{Mass Transfer Coefficient Calculation}

The mass transfer coefficient will be calculated as a function of rise time. In order to neglect any mass transfer that occurs during droplet formation, the shortest rise time for each experiment will be used as a reference. This reference rise time will be subtracted from all other rise times for the calculation of the mass transfer coefficient. Each experiment will be performed at 6 rise times, resulting in a set of 5 mass transfer coefficients per experiment. Assumptions made for calculating the coefficient are a constant aqueous phase volume, negligible species concentration gradient in aqueous phase, and constant droplet diameter within an experiment. It is assumed that there is a negligible change in the concentration of 
lanthanum and cerium in the aqueous phase because the amount that diffuses into the droplets is much smaller than the concentration that remains in the aqueous. The derivation of the equation for the mass transfer coefficient is included below.

The governing equations are those for the equilibrium of the species in each phase (equation 3 ) and accumulation of the species in the organic phase (equation 4).

$$
\begin{gathered}
C_{o, \varepsilon q}=m C_{a q, \theta q}=m C_{a q} \\
\frac{\partial C_{0}}{\partial t}=\frac{k A}{V_{0}}\left(C_{o, \theta q}-C_{o}\right)
\end{gathered}
$$

Where $\mathrm{C}$ is concentration, $\mathrm{m}$ is distribution coefficient, $\mathrm{k}$ is mass transfer coefficient, $\mathrm{V}$ is volume, $\mathrm{A}$ is interfacial surface area, and $\mathrm{t}$ is time. The subscripts $\mathrm{o}$, eq, and aq are representative of organic, equilibrium and aqueous conditions, respectively. Substitution of equation 3 into 4 and rearrangement, results in equation 5:

$$
\frac{\partial C_{o}}{\left(m C_{a q}-c_{0}\right)}=\frac{k A}{V_{o}} \partial t
$$

Equation 5

Since the shortest rise time $t_{\mathrm{R} 1}$ is to be used as a reference, the integration limits are for rise times of $t_{\mathrm{R} 1}$ to $t_{\mathrm{R} 2}$. Integrating equation 5 using these limits gives

$$
\ln \left(\frac{m C_{a q}-C_{o 1}}{m C_{a q}-C_{02}}\right)=\frac{k A}{V_{0}}\left(t_{R 2}-t_{R 1}\right)
$$

Equation 6

Where $\mathrm{C}_{\mathrm{o} 1}$ is the species concentration in the organic phase for the reference rise time. Rearrangement results in the equation used for the calculation of the mass transfer coefficients.

$$
k=\frac{V_{0}}{A\left(t_{R 2}-t_{R 1}\right)} \ln \left(\frac{m C_{a q}-C_{01}}{m C_{a q}-C_{o 2}}\right)
$$




\section{References}

1. Middleman, Stanley. An Introduction to Mass and Heat Transfer. John Wiley \& Sons. 1998. pp. 22-23. 